\title{
Pengaruh Syariah Marketing, Trust dan Complaint Handling terhadap Customer Financing Loyalty pada KSPS BMT Surya Sleman
}

\author{
Riza Kharisma, Abdul Salam, dan Rico Saktiawan Jang Jaya \\ Program Studi Ekonomi Syariah \\ Universitas Alma Ata \\ Jalan Brawijaya No.99, Yogyakarta 55183 \\ email: rizakharisma424@gmail.com
}

\begin{abstract}
This study aims to test and determine the influence of sharia marketing, trust and complaint handling to customer financial loyalty. Subjects in this study are active financing customers at KSPS BTMSurya PDM Sleman in 2017. There was 65 financing customers as this research sample, selected by using purposive sampling method. This study aims to prove, (1) does sharia marketing have a positive effect on customer financial loyalty, (2) does the trust have a positive effect on customer financial loyalty, (3) does the complaint handling have positive effect on customer financial loyalty, (4) does sharia marketing, trust and complaint handling have simultaneous effect on customer financial loyalty.

Based on $t$ test results, it can be seen that the variables of marketing sharia obtained $t$ value of $1.222<1.670$, thus it can be concluded that sharia marketing has no significant effect on customer financial loyalty. Trust variable obtained $t$ value $2.248>1.670$ thus it can be concluded that trust significantly influence the customer financial loyalty. Complaint handling variable obtained $t$ value arithmetic 3.208 $>1.670$ thus can be concluded that complaint handling had significant effect on customer financial loyalty. While the hypothesis testing can be seen that $\mathrm{f}$ arithmetic is 64,710 while $f$ table 2,76 with significant level 0,000>0,05. This means that all independent variables can influence the dependent variable all together toward customer financial loyalty.
\end{abstract}

Keywords : Sharia Marketing, Trust, Complaint Handling, Customer Financial Loyalty

\begin{abstract}
ABSTRAK
Penelitian ini bertujuan untuk menguji dan mengetahui pengaruh syariah marketing, trust dan complaint handling terhadap customer financing loyalty. Subjek dalam penelitian ini adalah nasabah pembiayaan yang aktif pada KSPS BTM Surya PDM Sleman tahun 2017. Dalam penelitian ini sampel berjumlah 65 nasabah pembiayaan yang dipilih menggunakan metode purposive sampling. Penelitian ini bertujuan untuk membuktikan, (1) Apakah syariah marketing berpengaruh positif terhadap customer financing loyalty, (2) Apakah trust berpengaruh positif terhadap customer financing loyalty, (3) Apakah complaint handling berpengaruh positif terhadap customer financing loyalty, (4) Apakah syariah marketing, trust dan complaint handling berpengaruh simultan terhadap customer financing loyalty.

Berdasarkan hasil uji t dapat diketahui bahwa variabel syariah marketing diperoleh nilai $t_{\text {hitung }}$ $1,222<1,670$, dengan demikian dapat disimpulkan bahwa syariah marketing tidak berpengaruh signifikan terhadap customer financing loyalty, variabel trust diperoleh nilai $t_{\text {hitung }} 2,248>1,670$ dapat disimpulkan bahwa trust berpengaruh signifikan terhadap customer financing loyalty, variabel complaint handling diperoleh nilai $t_{\text {hitung }} 3,208>1,670$ dapat disimpulkan bahwa complaint handling berpengaruh signifikan terhadap customer financing loyalty. Sedangkan dalam pengujian hipotesis dapat diketahui bahwa $\mathrm{f}_{\text {hitung }}$ sebesar 64,710 sedangkan $\mathrm{f}_{\text {tabel }} 2,76$ dengan tingkat signifikan 0,000 $>0,05$. Hal ini berarti bahwa semua variabel bebas secara bersama-sama mampu mempengaruhi variabel terikat customer financing loyalty.
\end{abstract}

Kata Kunci : Syariah Marketing, Trust, Complaint Handling, Customer Financing Loyalty 


\section{PENDAHULUAN}

Perekonomian suatu negara khususnya industri perbankan yang terdapat di Indonesia mengalami perkembangan yang signifikan, hal tersebut terlihat dengan kesuksessan Bank Muamalat Indonesia (BMI) sebagai perbankan syariah pertama yang beroperasi di Indonesia sejak 1 Mei 1992 dan terus mengalami perkembangan yang semakin pesat. Walaupun pada awal pendirian Bank Muamalat Indonesia (BMI) keberadaan bank syariah ini belum mendapat perhatian yang optimal dalam tatanan industri perbankan nasional (Antonio, 2001).

Keberadaan Perbankan disuatu negara merupakan salah satu agen pembangunan (agen of development) (Hasan, 2009), yaitu lembaga yang memobilisasi dana untuk pembangunan ekonomi dan melaksanakan tiga fungsi utama, seperti menerima simpanan uang, meminjamkan uang dan memberikan layanan jasa perbankan (Rivai dan Ismail, 2013).

Perkembangan industri perbankan syariah semakin pesat, baik dari cakupan wilayah jaringan kantor yang telah tersebar diseluruh penjuru Indonesia. Hal ini sebagai akibat dari peningkatan kebutuhan dan kesadaran masyarakat akan skema produkproduk yang ditawarkan dalam perbankan syariah, yaitu seperti produk penyaluran dana (financing), produk penghimpun dana (funding) dan produk jasa (services) (Sudarsono, 2015). Dimana produk-produk tersebut akan menjadi alternatif bagi penyelesaian masalah yang dihadapi oleh nasabah.

Terlebih dengan adanya undang-undang No. 21 Tahun 2008 tentang perbankan syariah yang dimana segala sesuatu yang menyangkut tentang bank syariah dan unit usaha syariah, mencakup kelembagaan, kegiatan usaha, serta cara dan proses dalam melaksanakan kegiatan usahanya (Ismail, 2011).

Produk penyaluran dana (financing) merupakan kajian yang masih sangat menarik dalam berbagai penelitian dan literatur perbankan syariah. Dimana produk penyaluran dana (financing) disini mempunyai pengaruh yang sangat besar terhadap pendapatan yang diterima oleh perbankan syariah dengan memiliki peluang dan berbagai tingkatan risiko yang harus bisa dikelola guna meminimalisir risiko tersebut. Penyaluran dana dalam perbankan syariah dikenal dengan istilah pembiayaan, dimana pembiayaan berdasarkan prinsip Islam adalah penyediaan uang atau tagihan yang dipersamakan dengan itu berdasarkan persetujuan atau kesepakatan antara bank dengan pihak lain yang mewajibkan pihak yang dibiayai untuk mengembalikan uang atau tagihan tersebut setelah jangka waktu tertentu dengan imbalan atau bagi hasil (Rivai dan Ismail, 2013). Menurut Ali (2008), produk penyaluran dana yang dilakukan oleh bank syariah pada prinsipnya dapat digolongkan menjadi 4 (empat) kategori yaitu: 1) Pembiayaan dengan prinsip jual beli, 2) Pembiayaan dengan prinsip sewa, 3) Pembiayaan dengan prinsip bagi hasil, dan 4) Pembiayaan dengan prinsip akad pelengkap.

Memasuki dekade tahun 2000 industri jasa pembiayaan di Indonesia mengalami perkembangan yang sangat pesat sehingga menuntut industri jasa pembiayaan dapat menyesuaikan diri dengan kebutuhan masyarakat terhadap pelayanan jasa keuangan yang sangat kompleks. Perkembangan industri jasa pembiayaan ini secara keseluruhan telah mampu menjadikannya sebagai suatu industri yang cukup menonjol dalam dunia bisnis khususnya sektor keuangan yang diperlukan dalam menunjang pembangunan ekonomi secara nasional (Muhaimin, 2012).

Disisi lain dengan adanya perbankan syariah munculnya lembaga keuangan mikro lainnya yang berbasis syariah yaitu BMT atau BTM. Baitul Maal wat Tamwil (BMT) atau Baitul Tamwil Muhammadiyah (BTM) telah menjadi istilah populer lembaga keuangan mikro berbasis syariah. Keberadaannya, menjadi alternatif akses pembiayaan, yang tidak ditangani oleh lembaga keuangan lainnya, seperti bank. Oleh karena itu, lini bisnis BMT/ BTM pada pembiayaan sektor usaha mikro dan kecil. Eksistesinya juga telah membantu usaha mikro, kecil, dan menengah (UMKM) (Ismanto, 2015).

Banyak faktor yang mempengaruhi keberlangsungan loyalitas nasabah 
BMT/BTM di Indonesia, yang dimaksud keberlangsung pada BMT/BTM adalah kemampuan lembaga untuk tetap hidup dan mampu bersaing dengan perbankan lainnya terutama bank konvensioal serta mampu melayani masyarakat dengan baik dengan cara mempertahankan kesetiaan nasabah atau loyalitas nasabah (Ismanto, 2015).

KSPS BTM Surya PDM Sleman merupakan salah satu lembaga amal usaha majlis ekonomi PDM Sleman yang telah didirikan sejak tahun 2010 di Gamping, Sleman. Sejak didirikan hingga saat ini cenderung mengalami perkembangan yang positif dilihat dari total aset. Berikut data yang menunjukan perkembangan total aset KSPS BTM Surya PDM Sleman:

Tabel 1

Data Perkembangan Total Aset KSPS BTM Surya PDM Sleman

\begin{tabular}{cc}
\hline Tahun & Total Aset \\
\hline 2013 & 1.727 .367 .204 \\
2014 & 2.477 .218 .003 \\
2015 & 2.930 .098 .303 \\
2016 & 4.367 .972 .339 \\
\hline
\end{tabular}

Sumber : BTM Surya PDM Sleman

Berdasarkan tabel 1 dapat dilihat perkembangan total aset pada tahun 2013 sampai 2016. KSPS BTM Surya PDM Sleman merupakan salah satu lembaga keuangan syariah yang berkembang pesat, untuk peningkatan aset tersebut disebabkan oleh bayaknya nasabah yang loyal terhadap KSPS BTM Surya PDM Sleman. Untuk mempertahankan loyalitas nasabah terhadap suatu pelayanan dilandasi oleh faktor-faktor tertentu diantaranya syariah marketing, trust dan complaint handling. Dengan marketing syariah yang berperilaku sesuai prinsip-prinsip syariah, trust yang maksimal dan complaint handling yang cepat tentunya kesetiaan nasabah terhadap KSPS BTM Surya PDM Sleman akan terus meningkat.

Berdasarkan latar belakang masalah tersebut maka penulis tertarik melakukan penelitian dengan judul "Pengaruh Syariah Marketing, Trust dan Complaint Handling Terhadap Customer Financing Loyalty Pada KSPS BTM Surya PDM Sleman.

\section{METODE PENELITIAN}

Penelitian ini yang menjadi populasi adalah nasabah pembiayaan yang aktif pada KSPS BTM Surya PDM Sleman berjumlah 175 nasabah pembiayaan pada tahun 2017.

Jumlah populasi dalam penelitian ini adalah sebanyak 175 nasabah pembiayaan, karena presentase kelonggaran yang digunakan adalah $10 \%$ dan hasil perhitungan dapat dibulatkan mencapai kesesuaian. Maka untuk mengetahui sampel penelitian, dengan perhitungan sebagai berikut:

$$
\begin{aligned}
& n=\frac{\mathrm{N}}{1+\mathrm{N} \mathrm{e}^{2}} \\
& n=\frac{175}{1+175(0,01)^{2}} \\
& n=\frac{175}{2,75} \\
& =63,63 \text { atau } 65 \text { Orang }
\end{aligned}
$$

Berdasarkan data yang diperoleh, jumlah populasi nasabah pembiayaan yang aktif di KSPS BTM Surya PDM Sleman adalah 175, jumlah sampel penelitian menggunakan margin of error sebesar $10 \%$ maka jumlah sampel Variabel (Y) yang diteliti adalah 63,63 dibulatkan menjadi 65 nasabah.

\section{HASIL DAN PEMBAHASAN}

\section{Analisis Deskriptif}

Penelitian ini dilakukan di KSPSBTMSurya PDM Sleman yang berada Jln. Raya Patukan, Ambarketawang,Gamping, Sleman. Penelitian ini berlangsung selama 9 hari, dimana peneliti juga secara langsung mendatangi nasabah ke rumah maupun lokasi tempat nasabah bekerja dengan tujuan untuk penyebaran kuesioner penelitian. Penyebaran kuesioner dilakukan mulai tanggal 12-21 April 2017 kepada 65 orang nasabah pembiayaan. Dalam hal ini, peneliti tentu saja melakukan koordinasi dan bantuan dari pihak KSPS BTM Surya PDMSleman untuk mendapatkan informasi lengkap mengenai nasabah pembiayaan. Berikut adalah profil responden: 
Tabel. 2

Berdasarkan Jenis Kelamin

\begin{tabular}{llcc}
\hline $\begin{array}{c}\text { Dasar } \\
\text { Klasifikasi }\end{array}$ & Sub Klasifikasi & Jumlah & Persentase \\
\hline \multirow{2}{*}{ Jenis } & Pria & 37 & 56,92 \\
Kelamin & Perempuan & 28 & 43,08 \\
& Total & 65 & 100 \\
\hline
\end{tabular}

Berdasarkan Tabel. 2 di atas, bahwa jumlah responden yang berjenis kelamin lakilaki sebanyak 37 orang dengan presentase $56,92 \%$, sedangkan responden dengan jenis kelamin perempuan berjumlah 28 orang dengan presentase $43,08 \%$.

Tabel. 3

Berdasarkan Usia

\begin{tabular}{cccc}
\hline $\begin{array}{c}\text { Dasar } \\
\text { Klasifikasi }\end{array}$ & Sub Klasifikasi & Jumlah & Persentase \\
\hline \multirow{4}{*}{ Usia } & $<20$ & 0 & 0 \\
& $21-30$ & 19 & 29,23 \\
& $31-40$ & 23 & 35,38 \\
& $41-50$ & 18 & 27,70 \\
& $>50$ & 5 & 7,69 \\
& Total & $\mathbf{6 5}$ & $\mathbf{1 0 0}$ \\
\hline
\end{tabular}

Berdasarkan tabel. 3 diatas bahwa jumlah responden usia $<20$ tidak ada, sedangkan yang usia 21-30 berjumlah 19 orang dengan presentase $29,23 \%$. Usia 31-40 berjumlah 23 orang dengan presentase $35,38 \%$ dan responden yang berusia 41-50 diperoleh 18 orang dengan presentase $27,70 \%$ dan sisanya diatas 50 tahun diperoleh 5 orang dengan presentase $7,69 \%$.

Tabel.4

Berdasarkan Pekerjaan

\begin{tabular}{clcr}
\hline $\begin{array}{c}\text { Dasar } \\
\text { Klasifikasi }\end{array}$ & Sub Klasifikasi & Jumlah & Persentase \\
\hline \multirow{5}{*}{ Pekerjaan } & Pelajar/Mahasiswa & 0 & 0 \\
& Pegawai Negeri & 1 & 1,54 \\
& Pegawai Swasta & 29 & 44,62 \\
& Wiraswasta & 12 & 18,46 \\
& Lain-lain & 23 & 35,38 \\
& Total & $\mathbf{6 5}$ & $\mathbf{1 0 0}$ \\
\hline
\end{tabular}

Klasifikasi responden yang keempat yaitu berdasarkan pekerjaan. Dimana dari data yang diperoleh peneliti, responden didominasi oleh nasabah pembiayaan dengan pekerjaan pegawai swasta sejumlah 29 orang, hal tersebut terlihat dari presentase
$44,62 \%$. Sedangkan untuk pekerjaan lainlain berjumlah 23 orang dengan presentase sebesar $35,38 \%$, untuk pekerjaan wiraswasta berjumlah 12 orang dengan presentase $18,46 \%$ dan yang paling rendah yaitu pegawai negeri yang berjumlah 1 orang dengan presentase $1,54 \%$.

Tabel. 5

Pendidikan Terakhir

\begin{tabular}{llcr}
\hline $\begin{array}{c}\text { Dasar } \\
\text { Klasifikasi }\end{array}$ & \multicolumn{1}{c}{$\begin{array}{c}\text { Sub } \\
\text { Klasifikasi }\end{array}$} & Jumlah & Persentase \\
\hline & SD & 8 & 12,31 \\
& SMP & 4 & 6,15 \\
Pendidikan & SMA & 48 & 73,84 \\
Terakhir & DIPLOMA & 0 & 0 \\
& SARJANA & 5 & 7,70 \\
& Total & $\mathbf{6 5}$ & $\mathbf{1 0 0}$ \\
\hline
\end{tabular}

Klasifikasi responden berdasarkan pendidikan terakhir yang dikelompokan menjadi 5 katagori, yang menunjukan bahwa mayoritas pendidikan terkahir yaitu SMA sebanyak 48 orang diperoleh persentase $73,84 \%$. Sedangkan SD dan SMP dan Sarjana sebanyak 17 orang atau dengan persentase $26,16 \%$.

Tabel. 6

Berdasarkan Jangka Waktu sebagai Nasabah

\begin{tabular}{llcr}
\hline $\begin{array}{c}\text { Dasar } \\
\text { Klasifikasi }\end{array}$ & Sub Klasifikasi & Jumlah & Persentase \\
\hline Jangka & $<1$ & 0 & 0 \\
Waktu & $1-2$ & 27 & 41,54 \\
sebagai & $>4$ & 17 & 26,15 \\
Nasabah & Total & 21 & 32,31 \\
& & $\mathbf{6 5}$ & $\mathbf{1 0 0}$ \\
\hline
\end{tabular}

Klasifikasi responden yang terakhir yaitu berdasarkan jangka waktu sebagai nasabah pembiayaan. Dimana dari data yang diperoleh peneliti dikelompokan menjadi 4 katagori yang menunjukan mayoritas 1-2 tahun sudah menjadi nasabah pembiayaan dengan presentase $41,54 \%$, sedangkan yang sudah 3-4 tahun sejumlah 17 orang dengan presentase $26,15 \%$ dan yang diatas 4 tahun sejumlah 21 orang dengan presentase $32,31 \%$. Hal ini menunjukan bahwa sebagian besar nasabah pembiayaan yang memiliki jangka waktu 1-2 tahun. 


\section{Uji Validitas}

Total responden sebanyak 65 orang dengan tingkat signifikansi sebesar 0,05 atau 5\%, maka diperoleh nilai $r$ tabel sebesar 0,2058 . Dengan demikian, dari keseluruhan item indikator variabel dalam penelitian ini diperoleh nilai Corrected Item-Total Correlation $>0,2058$ maka dapat disimpulkan bahwa keseluruhan item indikator variabel dinyatakan valid.

\section{Analisis Regresi Berganda}

Uji Regresi berganda digunakan untuk mengetahui seberapa besar pengaruh variabel bebas yang terdiri dari syariah marketing, trust dan complaint handling terhadap variabel terikat yaitu customer financing loyalty. Persamaan regresi adalah.

Analisis regresi berganda dalam penelitian ini menggunakan program SPSS versi 20.0 dapat dilihat pada Tabel dibawah ini:

Berdasarkan hasil pengolahan data seperti terlihat dalam tabel 7 pada kolom kedua Unstandardized Coefficients bagian B pada baris pertama diperoleh model persamaan regresi berganda adalah sebagai berikut :

$$
\begin{aligned}
& Y=3,420+0,155 \cdot X_{1}+0,442 \cdot X_{2}+0,631 X_{3}+e \\
& \text { Dimana: } \\
& \mathrm{Y} \quad=\text { Customer Financing Loyalty } \\
& \text { a } \quad=\text { Elemen Konstanta } \\
& \beta=\text { Koefisien Regresi Variabel } \\
& \text { Independen } \\
& \mathrm{X}_{1} \quad=\text { Syariah Marketing } \\
& \mathrm{X}_{2}=\text { Trust } \\
& \mathrm{X}_{3} \quad=\text { Complaint handling } \\
& \varepsilon \quad=\text { Error Of Term }
\end{aligned}
$$

\section{Uji Parsial (Uji T)}

Uji parsial digunakan untuk menunjukan seberapa jauh pengaruh satu variabel independen secara individual dalam menerangkan variasi variabel dependen.

Kriteria Pengambilan Keputusan

Jika nilai $\mathrm{t}_{\text {hitung }}>\mathrm{t}$ tabel maka hipotesis $\left(\mathrm{H}_{\mathrm{a}}\right)$ diterima ( $\mathrm{H}_{\mathrm{o}}^{\text {ditung }}$ ditolak)

Jika nilai $\mathrm{t}_{\text {hitung }}<\mathrm{t}$ tabel maka hipotesis $\left(\mathrm{H}_{\mathrm{a}}\right)$ ditolak $\left(\mathrm{H}_{\mathrm{o}}\right.$ diterima)

Jika nilai Sig. $>0,05$ maka hipotesis $\left(\mathrm{H}_{\mathrm{a}}\right)$ ditolak ( $\mathrm{H}_{\mathrm{o}}$ diterima $)$

Jika nilai Sig. $<0,05$ maka hipotesis $\left(\mathrm{H}_{\mathrm{a}}\right)$ diterima ( $\mathrm{H}_{\mathrm{o}}$ ditolak)

Berdasarkan Tabel 8 di atas, maka dapat ditarik kesimpulan:

\section{Syariah marketing}

Nilai hitung $_{\text {untuk }} X_{1}$ adalah 1,222. Sedangkan nilai $t_{\text {tabel }}$ pada alpha $=5 \%$, derajat kebebasan $(\mathrm{df})$ $=\mathrm{n}-\mathrm{k}-1$ adalah $(\mathrm{df})=65-3-1=61$ maka di dapat nilai 1,670. Berdasarkan tabel 4.10 diatas maka uji hipotesis ditemukan bahwa nilai koefisien dan $t_{\text {hitung }}$ positif. $T_{\text {hitung }} 1,222<t_{\text {tabel }} 1,670$. Diperoleh nilai signifikan untuk variabel Syariah marketing sebesar 0,227 >0,05. Dengan demikian syariah marketing tidak berpengaruh signifikan terhadap

\begin{tabular}{|c|c|c|c|c|c|}
\hline \multicolumn{6}{|c|}{ Coefficients $^{\mathrm{a}}$} \\
\hline \multirow{2}{*}{$\begin{array}{c}\text { Model } \\
\text { B }\end{array}$} & \multicolumn{2}{|c|}{$\begin{array}{l}\text { Unstandardized } \\
\text { Coefficients }\end{array}$} & \multirow[t]{2}{*}{$\begin{array}{l}\text { Standardized } \\
\text { Coefficients }\end{array}$} & \multirow[t]{2}{*}{$\mathrm{T}$} & \multirow[t]{2}{*}{ Sig. } \\
\hline & Std. Error & Beta & & & \\
\hline (Constant) & $-3,420$ & 3,169 & & $-1,079$ & ,285 \\
\hline Syariah Marketing & ,155 & ,127 & 143 & 1,222 & ,227 \\
\hline Trust & 442 & ,196 & 347 & 2,248 & , 028 \\
\hline Complaint handling & 631 & ,196 & 427 & 3,228 & ,002 \\
\hline
\end{tabular}
customer financing loyalty, maka Ha ditolak dan Ho diterima.

\section{Trust}

Nilait $_{\text {hitung }}$ untuk $X_{2}$ adalah 2,248. Sedangkan nilai $t_{\text {tabel }}$ pada alpha $=5 \%$, derajat kebebasan (df) $=\mathrm{n}-\mathrm{k}-1$ adalah $(\mathrm{df})=65-3-1=61$ maka di dapat nilai 1,670. Berdasarkan tabel 4.10 diatas maka uji

Tabel. 7

Analisis Regresi Berganda

Sumber: Data Primer Diolah 2017. 
Tabel. 8

Uji Parsial (Uji T)

\begin{tabular}{|c|c|c|c|c|c|c|}
\hline \multicolumn{7}{|c|}{ Coefficients $^{\mathrm{a}}$} \\
\hline & \multirow{2}{*}{$\begin{array}{c}\text { Model } \\
\text { B }\end{array}$} & \multicolumn{2}{|c|}{$\begin{array}{l}\text { Unstandardized } \\
\text { Coefficients }\end{array}$} & \multirow[t]{2}{*}{$\begin{array}{c}\text { Standardized } \\
\text { Coefficients }\end{array}$} & \multirow[t]{2}{*}{$\mathrm{T}$} & \multirow[t]{2}{*}{ Sig. } \\
\hline & & Std. Error & Beta & & & \\
\hline \multirow{4}{*}{1} & (Constant) & $-3,420$ & 3,169 & & $-1,079$ & ,285 \\
\hline & Syariah Marketing & ,155 & 127 & ,143 & 1,222 & 227 \\
\hline & Trust & ,442 & ,196 & ,347 & 2,248 & ,028 \\
\hline & Complaint handling & 631 & ,196 & ,427 & 3,228 & ,002 \\
\hline
\end{tabular}

Sumber: Data Primer diolah 2017.

hipotesis ditemukan bahwa nilai koefisien dan $\mathrm{t}_{\text {hitung }}$ positif. $\mathrm{T}_{\text {hitung }} 2,248>\mathrm{t}_{\text {tabel }} 1,670$. Diperoleh nilai signifikan untuk variabel trust sebesar $0,028<0,05$. Dengan demikian trust berpengaruh signifikan terhadap customer financing loyalty, maka Ho ditolak dan Ha diterima.

\section{Complaint handling}

Nilai $_{\text {hitung }}$ untuk $X_{3}$ adalah 3,228. Sedangkan nilai $\mathrm{t}_{\text {tabel }}$ pada alpha $=5 \%$, derajat kebebasan $(\mathrm{df})$ $=\mathrm{n}-\mathrm{k}-1$ adalah $(\mathrm{df})=65-3-1=61$ maka di dapat nilai 1,670. Berdasarkan tabel 4.10 diatas maka uji hipotesis ditemukan bahwa nilai koefisien dan $\mathrm{t}_{\text {hitung }}$ positif. $\mathrm{T}_{\text {hitung }} 3,228>\mathrm{t}_{\text {tabel }} 1,670$. Diperoleh nilai signifikan untuk variabel complaint handling sebesar sebesar 0,002 $<0,05$. Dengan demikianComplaint handling berpengaruh signifikan terhadap customer financing loyalty, maka Ho ditolak dan Ha diterima.

\section{Uji Simultan (Uji F)}

Uji simultan (uji F) digunakan untuk mengetahui apakah variabel independen secara bersama-sama berpengaruh secara siginifikan terhadap variabel dependen. Dimana untuk menentukan apakah variabel dinyatakan berpengaruh signifikan secara bersama-sama dapat dilihat dari apabila nilai $\mathrm{F}_{\text {hitung }}>\mathrm{F}_{\text {tabel }}$ dan sebaliknya. Berikut hasil uji simultan dapat dilihat pada Tabel 9 dibawah ini:

Tabel. 9

Uji Simultan (Uji F)

\begin{tabular}{cccccc}
\hline Model & $\begin{array}{c}\text { Sum of } \\
\text { Squares }\end{array}$ & Df & $\begin{array}{c}\text { Mean } \\
\text { Square }\end{array}$ & F & Sig. \\
\hline Regression & 1146,394 & 3 & 382,131 & 64,710 &, $000^{\mathrm{b}}$ \\
Residual & 360,221 & 61 & 5,905 & & \\
Total & 1506,615 & 64 & & & \\
\hline
\end{tabular}

Sumber:Data Primer diolah 2017.
Berdasarkan Tabel 9 di atas, diperoleh hasil bahwa nilai $\mathrm{F}_{\text {hitung }}$ sebesar 64,710 sedangkan $\mathrm{F}_{\text {tabel }}$ sebesar 2,76. Hasil tersebut membuktikan bahwa $\mathrm{F}_{\text {hitung }}>\mathrm{F}_{\text {tabel }}$ dengan demikian secara bersama-sama variabel syariah marketing $(\mathrm{X} 1)$, trust $(\mathrm{X} 2)$, dan complaint handling (X3) berpengaruh signifikan terhadap variabel customer financing loyalty (Y).

\section{Uji Determinasi (Uji R)}

Koefisien determinasi merupakan kemampuan suatu variabel bebas dalam menjelaskan variabel terikat. Dimana untuk menilai tingkat koefisien determinasi dapat dilihat pada nilai R Square yang dihasilkan. Ketika nilai R Square yang dihasilkan semakin mendekati angka satu (1) atau 1\%, maka dapat dinyatakan bahwa variabel bebas penelitian mampu menjelaskan variabel terikat secara kuat. Berikut hasil uji koefisien determinasi dapat dilihat pada Tabel dibawah ini:

Tabel 10

Hasil Uji Koefisien Determinasi

\begin{tabular}{cccc}
\hline Model & $\mathrm{R}$ & R Square & $\begin{array}{c}\text { Adjusted R } \\
\text { Square }\end{array}$ \\
\hline 1 &, $872^{\mathrm{a}}$ &, 761 &, 749 \\
\hline
\end{tabular}

Sumber: Data Primer diolah 2017.

Berdasarkan Tabel 10 di atas, diperoleh nilai $R$ Square sebesar 0,761 atau 76,1 \% yang berarti bahwa kemampuan variabel syariah marketing (X1), trust (X2), dan complaint handling (X3) dalam menjelaskan variabel customer financing loyalty $(\mathrm{Y})$ yaitu sebesar 76,1\%. Sedangkan sisa sebesar 23,9\% dijelaskan oleh variabel lain diluar variabel penelitian. 


\section{KESIMPULAN}

Berdasarkan pada analisis yang telah dilakukan terhadap data hasil penelitian, maka dapat diambil kesimpulan sebagai berikut:

1. Syariah marketing secara statistik tidak berpengaruh signifikan terhadap customer financing loyalty, hal ini dapat dilihat dari nilai koefisien regresi 0,155 dan nilai signifikan sebesar 0,227 dengan nilai a $=5 \%$

2. Trust secara statistik berpengaruh signifikan terhadap customer financing loyalty, hal ini dapat dilihat dari nilai koefisien regresi 0,442 dan nilai signifikan 0,028 dengan nilai $a=5 \%$

3. Complaint handling secara statistik berpengaruh signifikan terhadap customer financing loyalty, hal ini dapat dilihat dari nilai koefisien regresi 0,631 dan nilai signifikan 0,002 dengan nilai $\alpha=5 \%$

4. Berdasarkan pembahasan diatas bahwa nilai $\mathrm{F}_{\text {hitung }}$ sebesar 64,710 sedangkan $\mathrm{F}_{\text {tabel }}$ 2,76, hasil tersebut membuktikan bahwa $\mathrm{F}_{\text {hitung }}>\mathrm{F}_{\text {tabel' }}$ dengan demikian secara bersama-sama variabel syariah marketing, trust dan complaint handling berpengaruh signifikan terhadap variabel customer financing loyalty.

\section{DAFTAR PUSTAKA}

Antonio, Muhammad Syafi'i. 2001. Bank Syariah dari Teori ke Praktik. Gema Insani. Jakarta.

Abdur Rahman I. Doi. 1991 Inilah Syariah Islam. Pustaka Panji Mas. Jakarta.

Ali, Zainudding. 2008. Hukum Perbankan Syariah. Sinar Grafika. Jakarta

Alma, Buchari. 2011. Manajemen Pemasaran dan Pemasaran Jasa. Cv Alfabeta. Bandung.
Griffin, Jill. 2010. Customer Loyalty, Menumbuhkan dan Mempertahankan Pelanggan. Airlangga. Jakarta:

Hasan, Zubari. 2009. Undang-undang Perbankan Syariah. Rajawali Pers. Jakarta.

Ismail. 2011. Perbankan Syariah. Kencana. Jakarta.

Ismail, Rifqi dan Rivai, Veithzal. 2013. Islamic Risk Management for Islamic Bank. Gramedia. Jakarta.

Karsono. 2006. Pemikiran-pemikiran dalam Pembangunan Kesejahteraan Sosial. Lembaga Penerbit FE-UI. Jakarta.

Kau, Ah-Keng and Elizabeth Wan-Yiun Loh 2006. The Effects of Service Recovery on Consumer Satisfaction: a Comparison Between Complaint and Non Complaints. Journal of Service Marketing.Vol. 20 No. 2.

Kertajaya, Hermawan dan Syula, Muhammad Syakir. 2008. Syariah Marketing. Mizan. Bandung.

Kuat Ismanto, 2015, Faktor-faktor yang Mempengaruhi Eksistensi BMT/BTM di Pakalongan. Jurnal Libtang Kota Pekalongan Vol. 9. STAIN Pekalongan

Muhaimin, Perusahaan Pembiayaan Syariah di Indonesia. Jurnal Studi Ekonomi. Volume 3. Nomor 2. Desember 2012.

Philip Kotler, Manajemen Pemasaran, (Indonesia:PT Macanan Jaya Cemerlang, 2002), hlm. 15

,2009. Manajemen Pemasaran Jilid 1 Edisi 13. Erlangga. Jakarta

Ruslan, Rusadi. 2004. Manajemen Public Relations dan Media Komunikasi, PT. Rajagrafindo Persada. Jakarta.

Sudarsono, Heri. 2011. Bank dan Lembaga Keuangan. Ekonisia. Yogyakarta 